\title{
Ocean Acidification and Carbonate System Geochemistry in the Arabian Gulf
}

\author{
Jassem A. Al-Thani', Connor Izumi², Oguz Yigiterhan'1, Ebrahim Mohd A S Al-Ansari', Ponnumony \\ Vethamony ${ }^{1}$, Caesar Flonasca Sorino', Dan Anderson², James W. Murray ${ }^{2}$
}

1. Environmental Science Center, Qatar University, Doha, Qatar 2. School of Oceanography, University of Washington, Seattle WA. USA

\section{ABSTRACT}

\begin{abstract}
Alkalinity (Alk) and (Dissolved Inorganic Carbon) DIC were measured on high resolution seawater samples, collected on November 2018 and May 2019 at seven stations in the Exclusive Economic Zone (EEZ) of Qatar. Calculated surface $\mathrm{P}_{\mathrm{CO} 2}$ averaged 472 ratm in 2018 and $447 \mu$ atm in 2019 .

Thus: the Arabian Gulf is degassing $\mathrm{CO}_{2}$ at present and will not take up atmospheric $\mathrm{CO}_{2}$ until 2042. Ocean acidification is not yet an issue in the EEZ of Qatar.

The elevated $\mathrm{P}_{\mathrm{CO} 2}$ values are due to $\mathrm{CaCO}_{3}$ formation. Normalized NAlk and NDIC were calculated to remove the impact of increasing salinity. NAlk and NDIC decrease corresponding to $\mathrm{a} \mathrm{CaCO}_{3} / \mathrm{OrgC}$ removal ratio of $2 / 1$. We calculated the nitrate corrected and salinity normalized tracer, Alk* ${ }^{*}$. Values of Alk* were negative, and the change in Alk* relative to Hormuz (DAlk*) indicated that there has been an average decrease of Alk* of $-130 \mathrm{mmo}$ $\mathrm{kg}^{-1}$. This decrease is due to $\mathrm{CaCO}_{3}$ formation but previous studies found no evidence for coccolithophorids. One obvious possibility is that Alk removal is due to $\mathrm{CaCO}_{3}$ formation in coral reefs. However, recent study of the composition of particulate matter found that the average particulate Ca concentration was $3.6 \%$, and was easily acid soluble (Yigiterhan et al, 2018). These results suggest that a significant amount of particulate $\mathrm{CaCO}_{3}$ is present in the water column. One hypothesis is that the particulate $\mathrm{Ca}$ comes from carbonate rich atmospheric dust. Using Al as a tracer for dust and the average Ca/Al ratio in Qatari dust can only explain about $3 \%$ of the particulate $\mathrm{Ca}$. An alternative hypothesis is that particulate $\mathrm{CaCO}_{3}$ may form in the water column due to abiological $\mathrm{CaCO}_{3}$ formation, as proposed large inputs of nucleation sites in the form of atmospheric dust.
\end{abstract}

\section{LITERATURE REVIEW}

Historical data from 1977

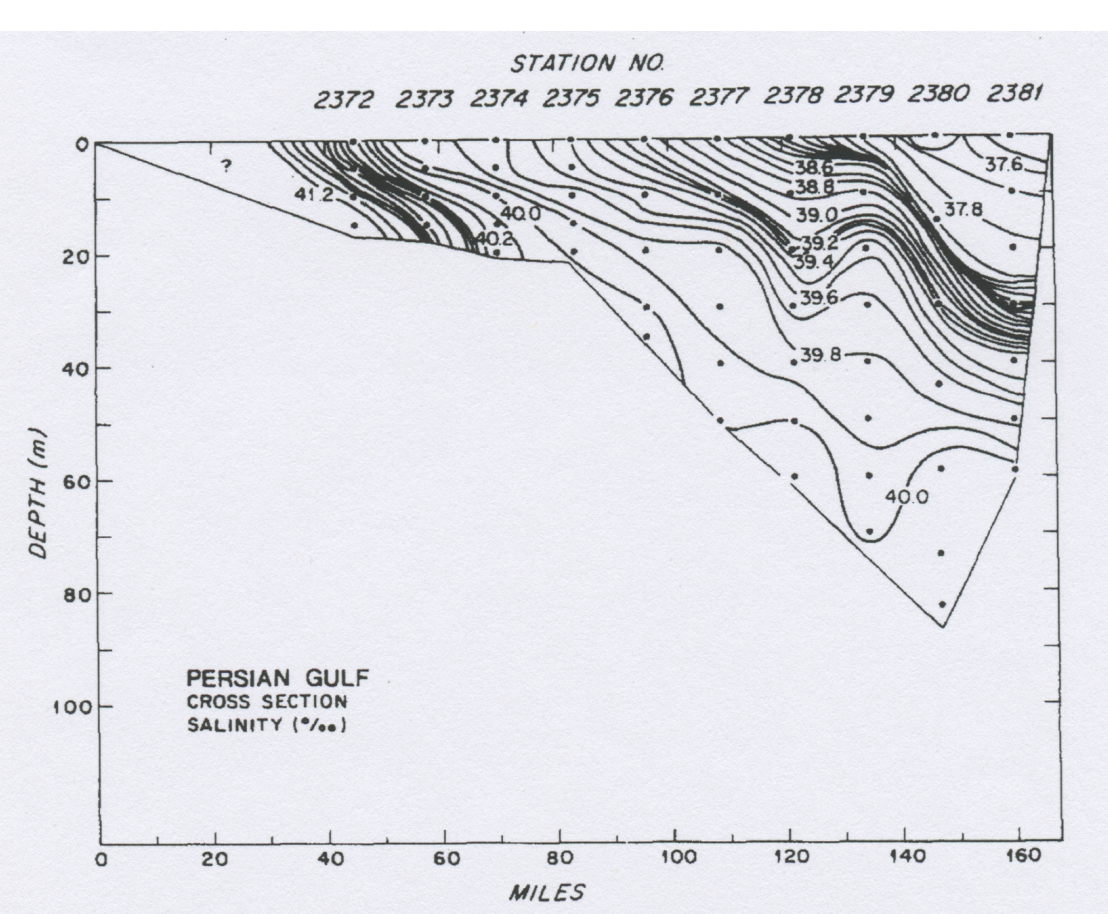

Fig. 2: Surface $S$ in the Gulf

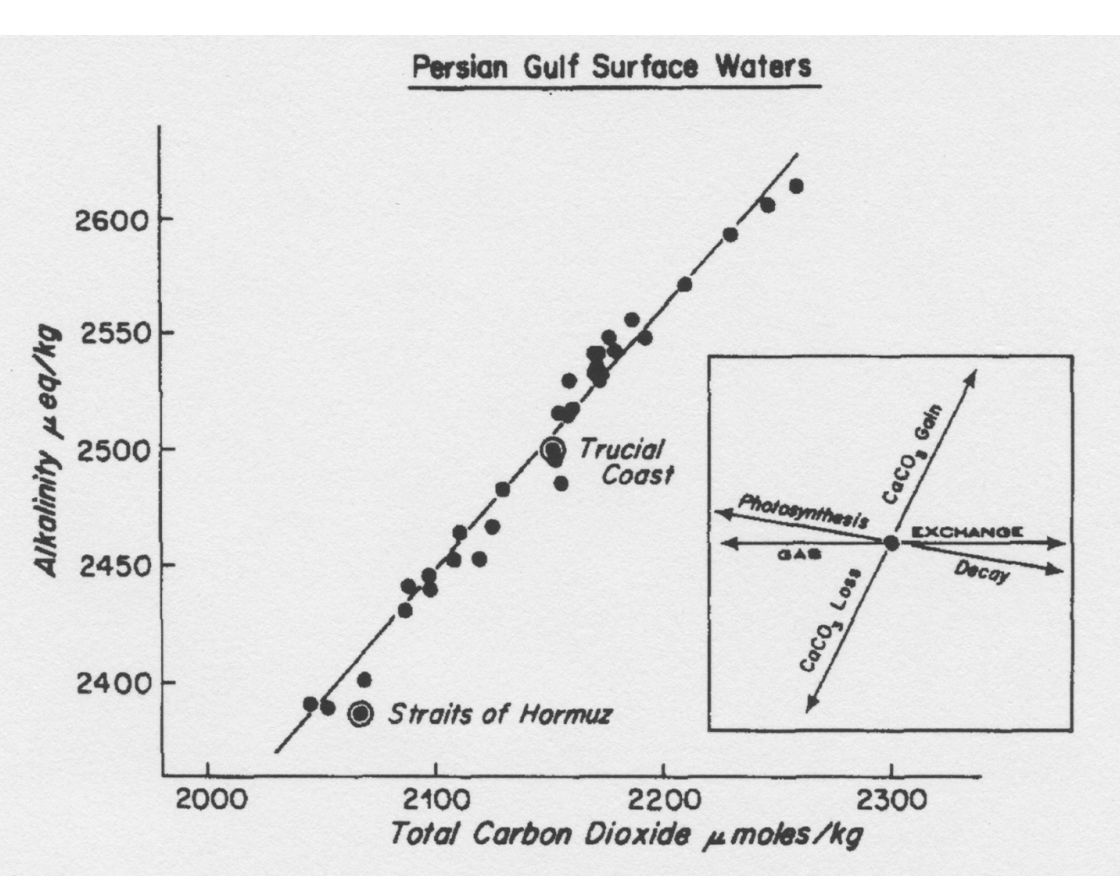

Fig. 4: Alk versus DIC

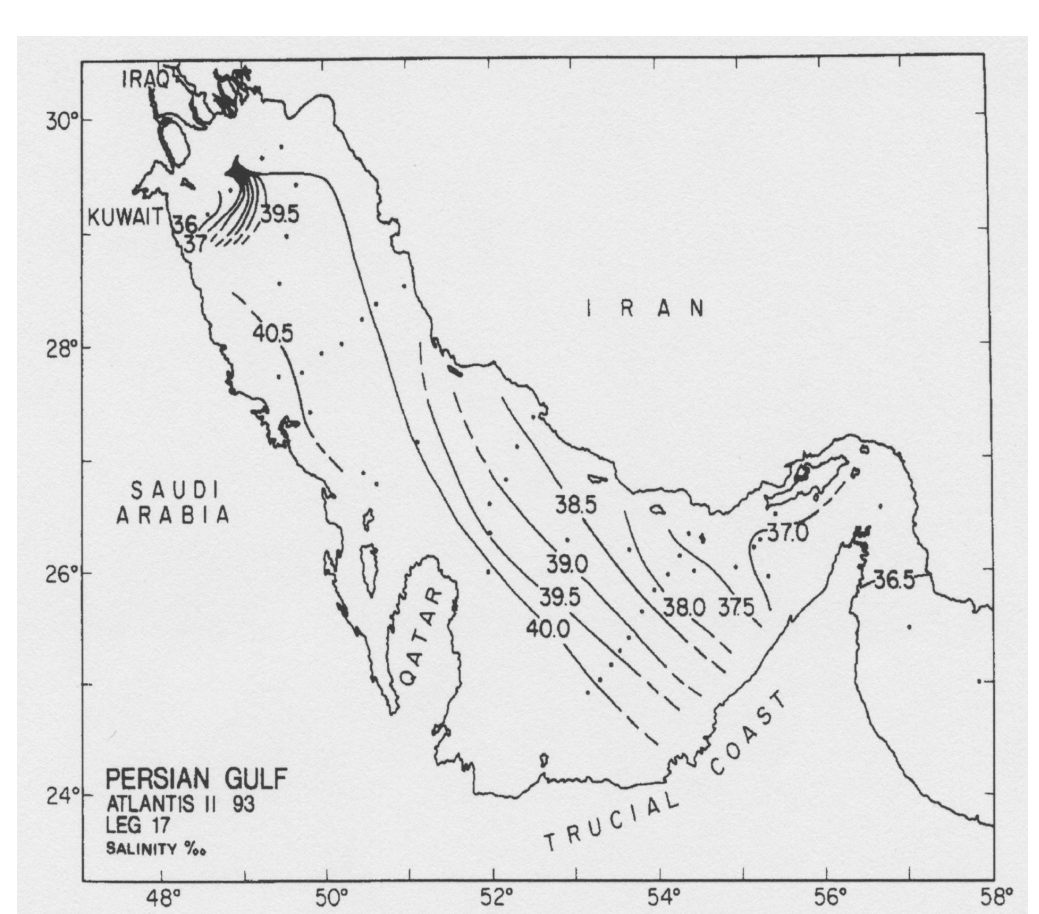

Fig. 3: Salinity (S) - Depth section



Fig. 5: NAlk versus NDIC

\section{METHODOLOGY}

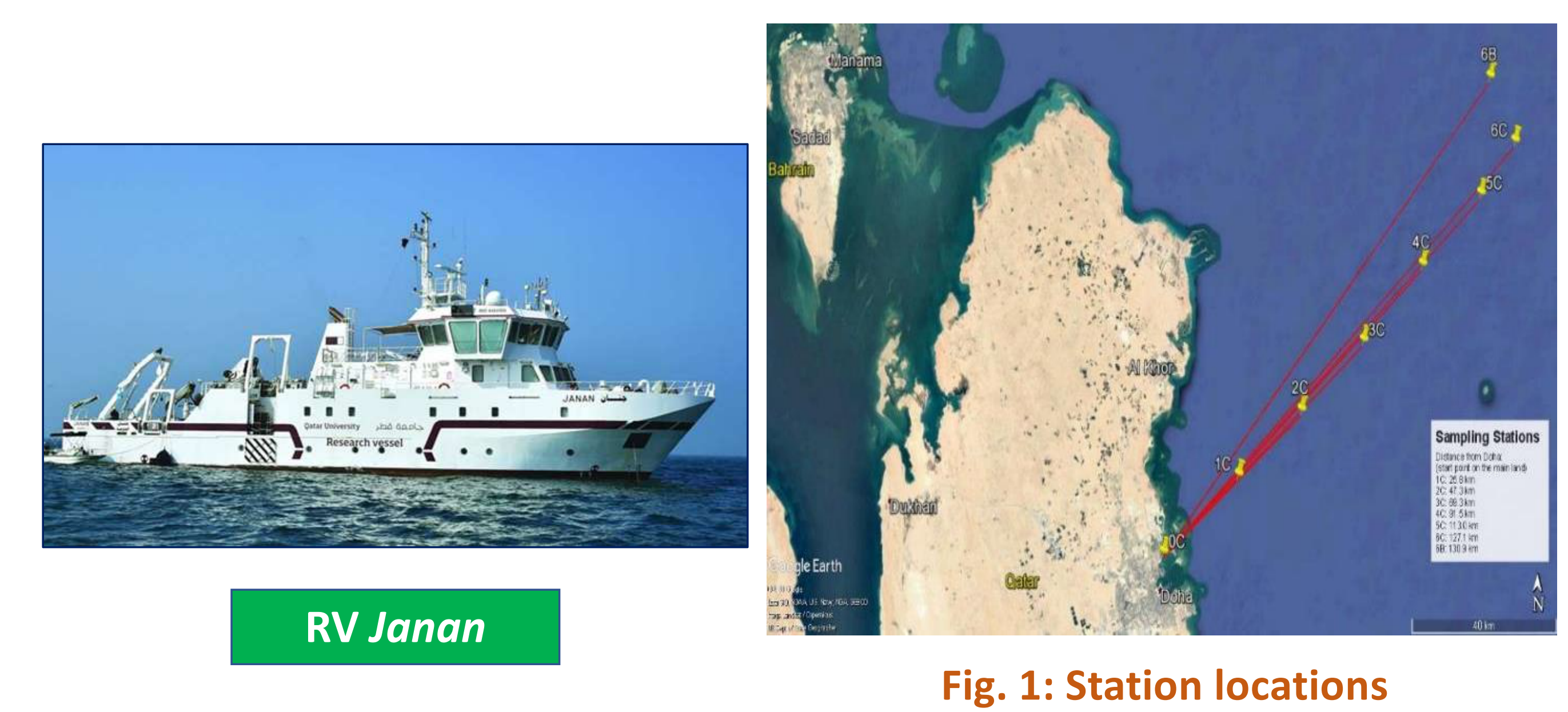
the Arabian Gulf sampled on November 2018 and May 2019 by ESC Team, on board $R / V$ Janan.

ANALYTICAL METHODS

DIC was measured by coulometry

Alkalinity (Alk) was measured by titration. Dickson standards were used.

\section{REFERENCES}

1. Brewer and Dyrssen (1985). Progress in Oceanography 14, pp 41-55

2. Wanninkhof and McGillis (1999). GRL 26, pp 1889 - 1892

3. Wurgaft, Steiner, Luz and Lazar (2016). Marine Chemistry 186, pp 146-155

4. Yigiterhan et al (2018). Chemical Geology 476, pp 24-45 in the Qatar Exclusive Economic Zone in

\section{RESULTS}

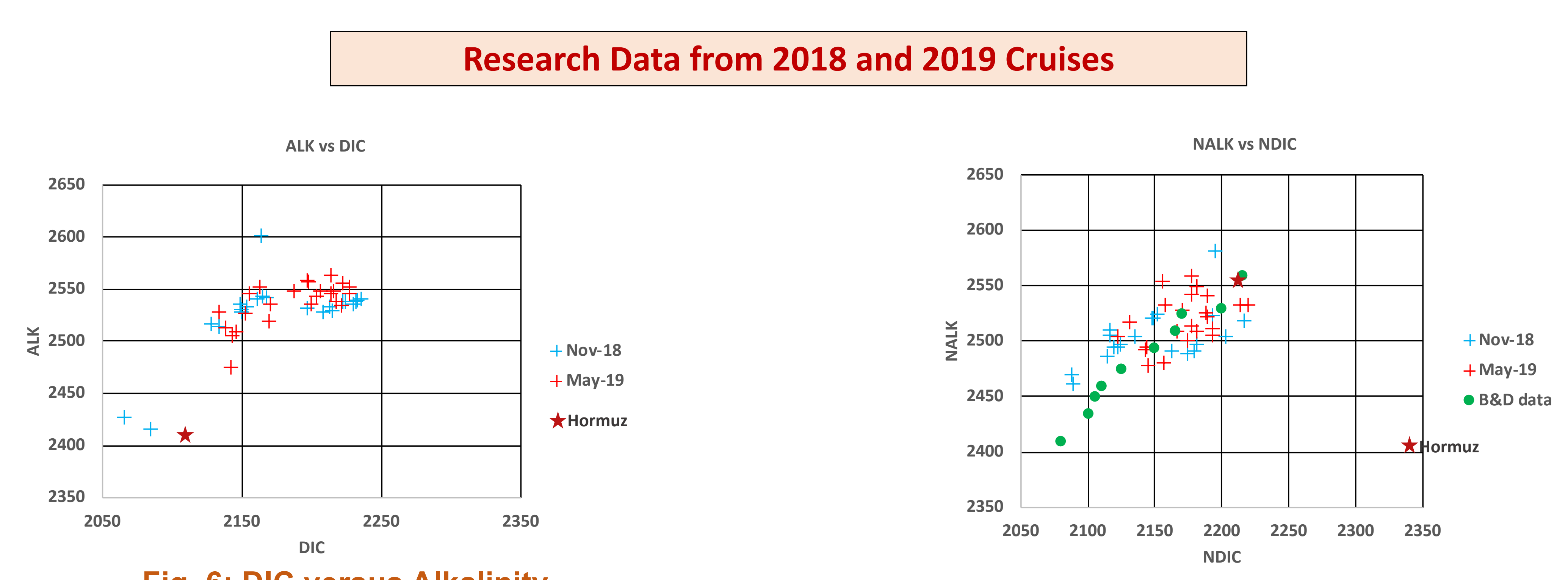

Fig. 6: DIC versus Alkalinity

The red star is the value for inflow through the Strait of Hormuz from Brewer \& from Hormuz to Qatar EEZ due to salinity increase.



Fig. 8: Calculate Alk*

Plot of $\triangle$ Alk* relative to Strait of Hormuz.

1. Calculate Potential Alkalinity:

$A_{P}=A_{T}+1.26 \times N^{2}$

2. Normalize to $S=40$

$A_{P}^{C}=S \times A_{p} / S$

3. Then: $\quad$ Alk $^{*}=A_{p}-A_{P}^{c}$

ALK* is negative

$\triangle \mathrm{Alk}^{*}$ is negative (relative to Hormuz) show that there has been no change since 1977 .
When the impact of salinity is removed, NDIC and NAIK decrease from Hormuz to Qatar EEZ. The slope is due to $\triangle \mathrm{CaCO}_{3} / \Delta \mathrm{OrgC}=2$. The data from Brewer and Dyrssen (1985)

\begin{tabular}{|c|}
\hline $\begin{array}{l}\qquad \mathrm{CaCO}_{3} \text { Formation: } \\
\text { Alk versus DIC and NAlk versus NDIC } \\
\text { Data from } 1977 \text { by Brewer and Dyrsen (1985) } \\
\text { Insert shows vectors for specific processes } \\
\text { For this data set the decrease in NAlk and NDIC } \\
\text { correspond to a } \mathrm{CaCO}_{3} \text { removal / Photosynthesis ratio of 2:1 }\end{array}$ \\
\hline $\begin{array}{l}\text { Reverse Estuarine Circulation: } \\
\text { Surface Seawater enters through the Strait of Hormuz and } \\
\text { salinity increases to the north because of large net } \\
\text { evaporation. The high salinity return flow to the south exits } \\
\text { the Strait of Hormuz at depth, by Brewer and Dyrssen (1985). }\end{array}$ \\
\hline $\begin{array}{l}\text { Calculation of Gas Exchange Flux of } \mathrm{CO}_{2} \\
\text { The gas exchange flux of } \mathrm{CO}_{2} \text { equals the rate of } \mathrm{CaCO}_{3} \\
\text { formation. We calculated the flux of } \mathrm{CO}_{2} \text { using the stagnant } \\
\text { boundary layer model and piston velocity from Wanninkhof } \\
\text { (1999). Assuming an average wind speed of } 10 \text { knots, the } \mathrm{CO}_{2} \\
\text { flux equals } 6.9 \text { mol } \mathrm{C} \mathrm{m}^{-2} \mathrm{y}^{-1} \text {. This is much greater than the rate } \\
\text { of net calcification seen for pristine corals. }\end{array}$ \\
\hline
\end{tabular}

\section{DISCUSSION}

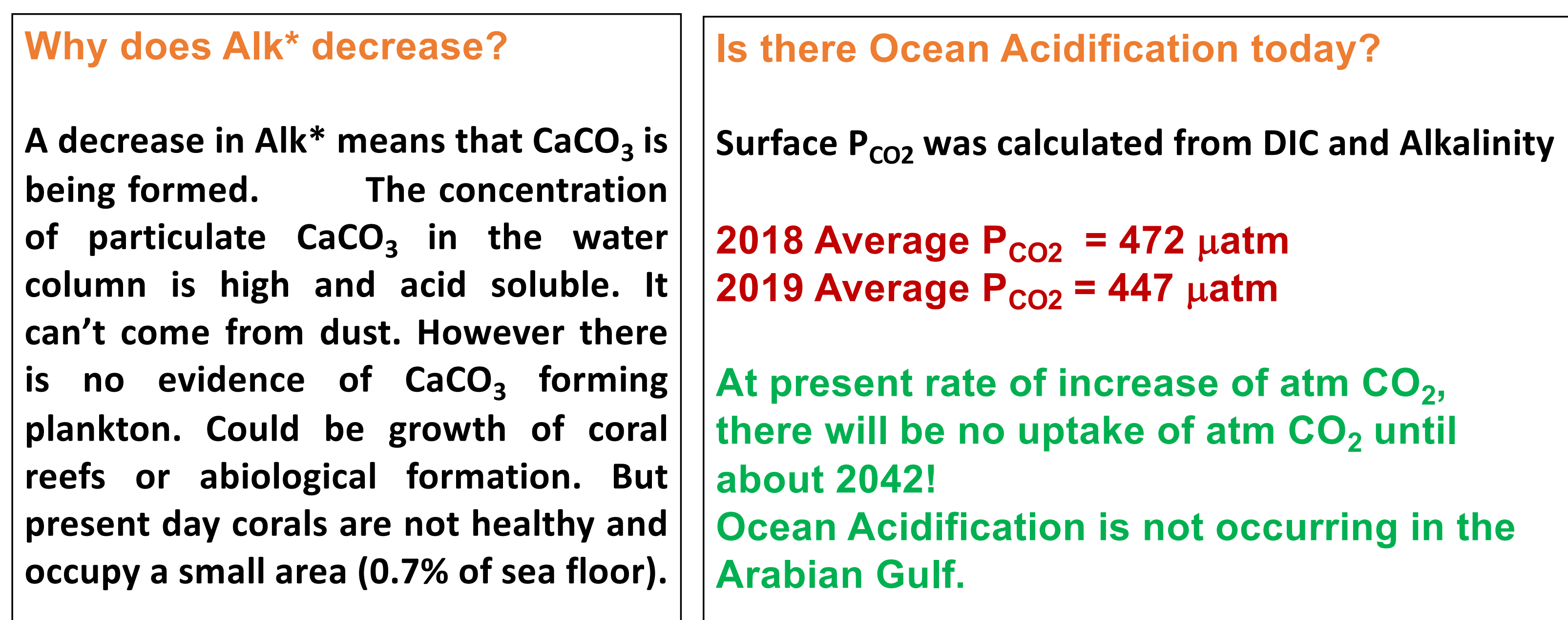

Why is $\mathrm{P}_{\mathrm{CO} 2}$ so high?

Due to $\mathrm{CaCO}_{3}$ formation and this reaction: $\mathrm{CaCO}_{3}+\mathrm{CO}_{2}+\mathrm{H}_{2} \mathrm{O}=$ $2 \mathrm{HCO}_{3}{ }^{-}+\mathrm{Ca}^{2+}$

\section{CONCLUSION}

1. $P_{\mathrm{CO} 2}$ in the surface water of the Arabian Gulf is higher than atmospheric.

2. Ocean Acidification is not a present issue.

2. The tracer DAlk* is negative suggesting that $\mathrm{CaCO}_{3}$ formation is occurring

3. $\mathrm{P}_{\mathrm{CO} 2}$ is high because of $\mathrm{CaCO}_{3}$ formation. There is high particulate $\mathrm{CaCO}_{3}$ but there are no $\mathrm{CaCO}_{3}$ forming plankton It can't come from dust.

4. It could be growth of coral reefs or abiological formation

5. Coral reefs in the Arabian Gulf are not healthy.

6. The rate of calcification can be calculated from the gas exchange flux of $\mathrm{CO}_{2}$

7. Assuming average winds, the gas exchange flux of $\mathrm{CO}_{2}$ (and rate of formation of $\mathrm{CaCO}_{3}$ ) equals $6.9 \mathrm{~mol} \mathrm{C} \mathrm{m}^{-2} \mathrm{y}^{-1}$

8. This is much greater than previously measured net calcification rates of healthy coral reefs in other locations.

9. Abiological $\mathrm{CaCO}_{3}$ formation appears to be a possibility!

\section{ACKNOWLEDGMENT}

The authors would like to thank Qatar University Office of Academic Research for funding and supporting International Research Collaboration CoFunds (IRCC-2019-002) . The dedicated effort exerted by the Captain and crew of Qatar University R/V Janan during sampling was greatly appreciated. We highly appreciate Qatar University - Environmental Sciences Center administration and staff for supporting this project at various 